\title{
Research methodologies appropriate to rapid appraisal: a Chinese experience
}

\author{
Elisabeth J. Croll
}

\section{Introduction}

In any field research on rural women, the choice of the means of eliciting information will be determined by the social context and the focus of the enquiry, the amount of background data available to the researcher and the time (including preparation time) to be allocated to the study. Until quite recently virtually no sociological surveys or fieldwork studies were carried out in China; nowadays sociologists from abroad can get access but they are normally only issued with a visa for a month or so, so fieldwork has to be undertaken rather rapidly. One way of gathering detailed data from the rural village, the urban neighbourhood, the peasant or city household is the rapid survey. Since the time constraint calls for great efficiency of research effort, the experience of rapid household surveys in China is of considerable value to those considering the process of rapid appraisal itself. Although in the case of China a number of particular constraints affect research undertaken there, these are not unique to that country.

China is a highly organised society, and this greatly faciltates the initial entry of the researcher into the village or urban neighbourhood and the setting up of the research. However, the Chinese Government also attaches a number of conditions to access: firstly it defines the type and focus of the research and tends to prefer subjects which have social policy implications. There is then a direct benefit in terms of feedback. Where possible the government also hopes that the sociologist from abroad will contribute to the training of young researchers while carrying out fieldwork. The location of the research is negotiated between the host and the researcher.

In most socialist states a major problem researchers have to confront is the clear and explicit ideology concerning the role of social institutions and gender relations. For example there is a clear ideology about how the household ought to be constituted, and how relations between the generations and sexes ought to be conducted. It is thus very difficult to identify what actually 'is' as opposed to what 'ought to be'. Levi Strauss [1953] noted that fieldwork is most difficult where a clearly defined ideology represents social structures and social processes as they 'ought to be'.

Any rapid social surveys on whatever topic must not be isolated from a wider body of explanation and argument. Ideally they should be undertaken within the context of a much larger study. Rapid appraisal can be considered as the icing on a very substantial cake which contains a thorough acquaintance with the documentation of the society and/or the topic of enquiry. Several months, even a year or two may have been spent on the background research and the development of hypotheses before field investigation begins. At the very least, prior study should identify a number of specific questions requiring answers in the field. Rapid rural appraisal implies that the research design has to incorporate its own safeguards to reduce error to a minimum, as so often data cannot be checked once the researcher leaves the field. In sum, thorough preparation is probably the most single important precondition of the success of rapid appraisal.

Another important question to be considered prior to the survey is how the data obtained from rapid appraisal are to be utilised. Can they stand as the basis for argument or the testing of a hypothesis? Much will depend on the scale of enquiry. For China scholars, the limits on field research and the scale and diversity of local conditions means that it is often best to use field research as an additional, more detailed case study to add to others already gleaned from documentary materials. Part of the problem of generalising about China is that any local data are very area-specific.

\section{Two Field Studies in China}

The first field research experience I want to dscribe took place in 1977.1 made a rapid survey of household composition as part of a larger documentary study of

IDS Bulletin. 1984, vol 15 no 1, Institute of Development Studies. Sussex 
marriage in which I was looking at how marriage is negotiated and by whom, the pre-marital rituals of courtship and betrothal, age at marriage, the criteria, the ceremonial and the presentations which took place at the time of the contract [Croll 1977]. Initially, most observers gained the general impression that 'free choice marriage', written into the Marriage Law of 1950, was widely practised. However, during the preliminary documentary research, which correlated variations in marriage negotiations with different household forms and also with the value accorded to women's labour, certain hypotheses began to emerge. It appeared that the processes of collectivisation and the economic functions which continued to be demanded of peasant households might well have actually strengthened households and kinship groups and caused them to be more complex in structure and more cohesive than they had been before 1950. This trend had tended to strengthen the elders's control of familial affairs and to make for the continuation of arranged or semi-arranged marriage rather than the establishment of free-choice marriage as the law stipulated.

This hypothesis challenged the interpretations of sociologists who had worked on China before, and who had assumed that the peasant household was declining in size and function as a result of collectivisation [Croll 1981:144-5], and that kinship groups were more or less defunct because of their re-organisation into production teams and brigades [Croll 1981:167]. This hypothesis could only be developed tentatively, because there had been no substantial data on household size and composition published since the 1930s and 1940s. Although the household is the most universal institution in China, economists and political scientists had looked at it only very rarely, favouring communes, production brigades and production teams. For this reason I wanted to make a complete household survey of one village in order to understand household composition, how the household is defined by its occupants, to establish its size, and the age, sex, and occupations of its members, its kin relations within the village, as well as age at marriage, the wife's origins and her surname. I actually asked a very small set of questions: only those for which documentary research provided no answers. The negotiation of marriage and the selection process could be pieced together from documentary sources, but no picture of the size, structure and function of the household emerged from an intensive study of newspapers, radio reports and other sources.

To further refine down my field of enquiry I visited a number of localities and interviewed commune, production brigade and production team cadres. After several household interviews in each of the five or six villages, I chose one particular village for further study, in part because it was small enough to allow for a survey of all households in the limited time available. A single tightly structured questionnaire, designed to acquire basic demographic information, was used in each household to elicit basic data on household composition; age and occupations of household members, nearest kin and proximity of residence; wife's surname. Research in China has certain advantages such as well-defined categories and clear definitions of, for example, occupation and employment, so that some of the definitional problems that plague researchers in other societies are less commonly met. As elsewhere though, there can be some definitional confusion between the household $(h u)$ and the family (jia) which had to be clarified at the outset.

Prior questioning at the higher administrative levels of the commune, brigade and team enabled me to compare data from the village with those from the commune and the production team. An interesting normative discrepancy between these two sources emerged. At the commune and team level, cadres said that young people normally got married at a certain age, and that people with the same surname did not normally marry. However, when questioning married couples about the wife's origins, her surname, and age at marriage, quite large differences appeared between what cadres thought was happening and what was actually occurring in the village.

Although some direct questioning was possible, there were areas where indirect methods of getting information were more appropriate. For instance $\mathbf{I}$ was interested in the transfer of betrothal gifts and dowries. At the time, documentary materials provided little evidence of the persistence of this custom and, given that the practice had been outlawed, direct questioning about such exchanges was impossible. However, on asking to see around the house, I was taken directly to the newly married couple's bedroom, where on display was all the furniture, the bedding, the case of clothes, and so on. Household members would quite spontaneously relate the origins and cost of the items, and explain how much was from the wife's or groom's family and the value of each contribution.

Some questions had to be dropped because they were inappropriate in the context of a rapid survey, largely due to the strong normative ideology. An example is women's domestic labour and the control of budgeting: the prevailing ideology at the time held that everybody in the household should share the housework and that families should be democratic about budgeting decisions. Questions around these topics received a virtually identical and ideologically constructed answer, so after the first two or three households I simply dropped them from the list. 
Useful information on these areas could only have been gained from longer periods of observation.

The aid of local cadres was indispensable for acquiring data rapidly and efficiently, but the most helpful informants were in fact educated, urban teenagers who were living and working in the villages. They were delighted to be asked to help. Although they were not entrusted with interviewing, I asked them to draw maps of the village and to label every single household. In that way the location of each household was pinpointed and I could be quite systematic about ensuring that all were visited.

The result of this first experience validated the use of a rapid appraisal method in household surveys. Indeed I still feel they should play a very important part in any social research in China. The fact that political scientists and economists frequently only talked to cadres, often led to a situation in which their fieldnotes differed little from what could be gleaned from a study of local newspapers or any other documentary source. Research reported at this level was very often disappointing. Political scientists and economists ignored households, yet if they are looking at education, for example, it is in the households that the consumers of the education service live. Questions such as what schools their children attend, what their educational plans are, what they anticipate in terms of age and achievement, could inform and illuminate their research.

My second trip was in 1980 and was much more ambitious; the research included not only household composition but also income, food expenditure, diet and food habits [Croll 1982a, 1982b]. It was undertaken in conjunction with professional sociologists in China, for by this date Institutes of Sociology had been reinstituted. The context of the fieldwork was a documentary study on the family rice bowl. The research was designed to examine the circuits of food supplies to the household and the mechanisms of the state, the collective and the market which determined what foodstuffs were produced and/or processed by the household itself, allocated to the household by collectives and the state, or purchased by the household from the various markets and shops.

The first year of the study was allocated to background documentary research, to analysing the principles and politics underlying the national food system in China and how these were likely to affect the livelihood of the individual household. For instance one focus was the rationing system, since all staple foods are allocated by the state to households in both urban and rural areas. Another was the degree to which households are self-provisioning, what kind of land they have access to, what kind of food they produce and process for themselves and who undertakes the production and processing. In urban areas the focus was on the retail outlets and shopping habits (an aspect very often left out of food systems studies) and the sexual division of labour. In many planned economies it has been very difficult for householders, usually women, to procure sufficient food to feed their families, let alone to process and cook it.

One of the most interesting findings was the correlation between the labour resources of a household and the size and components of the family food bowl. The amount of labour available and how it is organised - to cultivate plots of land, to rear domestic livestock and to purchase, process and cook foodstuffs - are basic factors affecting the economy and food resources of the peasant household. Again it seemed that a series of household surveys was probably the best way to elicit the relevant data in a short time, and to provide some specific case studies which could be added both to the very general data on how the food system operated and to the case studies already made.

This time the scope and focus of the research suggested that the household surveys should be contextualised by looking at food circuits in some detail first, and only after this by surveying particular households. In rural areas this was achieved by asking commune and production team leaders very specific questions about local food supplies and availability for consumption. How self-sufficient were households, what was purchased, what was bought into the commune, what was their understanding of per capita or household food consumption? How much time and income did they think households spent actually procuring their own food? These data provided a general idea of the area and of what cadres thought happened in the village. Then all the shops and markets in that particular area were visited and shopkeepers asked about the types and availability of food supplies and how much people usually spent on each visit, what they purchased etc. Frequently the research included shopping for a typical day's menu in the state food shops and the free peasant markets. For staple foods rural grain stations were visited and questions asked about supplies and rations.

In the household survey my first aim was to build up base-line data on households in terms of composition, the development cycle, occupation, family size and proximity of kin. These questions are generally very straightforward once the family (jia) is differentiated from the household $(h u)$. The introduction of informants to the researcher is a good way of both establishing this difference and some degree of rapport. One reason why it was then possible to elicit 
information on very personal matters was that everybody in the village knew about everybody else and before 1981 there was no private tax system. Taxes were paid by the collective so that people did not have any incentive to evade answering certain questions. Moreoever, the range of income within a village was very small, because there had been a considerable degree of equalisation within villages.

The second section of the questionnaire concerned income, both from official sources - wages, bonuses etc - and from informal sources such as family or domestic sidelines in the rural areas. Questions were included on grain rations, reserves and surplus: how much was received, consumed and stored as surplus during each month? Again, this kind of information is easy to elicit quickly as household distribution and consumption is still very carefully calculated. For instance grain consumed at each meal is measured so everyone knows exactly how much goes into the cooking pot. Finally, a section on the production and purchase of vegetables and meat was included to cover frequency of purchase whether in state shops or private markets; the length of time allocated to cooking the food, feeding the livestock and cultivating the vegetables etc.

In the urban areas similar interviews were conducted at the city level in the grain, vegetable and meat bureaux. What are the measures of their calculations for supplying the city population and how much is brought into the cities for consumption? What do the bureaux expect people to purchase each day? Again, supplies and consumption are planned. A smaller area within a city was then selected and all the food shops within that particular area visited. Again retail out lets make very careful calculations and in some cases they actually had charts up on the wall for the customers to see how much the shop expected to sell, how many customers they had, what each customer purchased etc. Finally, the level of enquiry was narrowed down to the households and many of the same questions asked as in the peasant households.

One of the aims of the research was to ascertain the demands of national food policies on female labour. Hence an area of questioning in each household centred on the sexual division of labour in the procuring and processing of foods. As in the first survey no general information on the sharing of labour was solicited, and interestingly, in this second survey there were fewer spontaneous references by informants to the norms of sharing. Detailed questioning on the relative amounts of time spent by men and women in each phase of food provisioning allowed for documentation of the intra-familial distribution of labour [Croll 1982b:312-17].
The research was designed to include four surveys: two urban, two rural, with one pair in the north and one pair in the south of China in order to take account of the fact that the south is mainly rice-eating and riceproducing and the north is mainly wheat producing, and cereals, noodles and breads are consumed. Within these constraints the four locations were chosen by the Academy of Social Sciences, but within each field there was some choice in terms of the selection of the households for interview. In such cases it was necessary to establish why a particular village or neighbourhood had been chosen by the host. In my study two alternative methods of determining choice of location were used. Where the sociologists had chosen the area, they had usually had interesting reasons for doing so, which were quite important in terms of background to the survey. They had perhaps deliberately chosen an urban neighbourhood which had a wide range of occupations and a proportion of intellectuals, cadres, and factory workers. Where the government had chosen the area, it was frequently one that had been much visited by foreigners before, and the selection of the households became more of a problem. Very often the local cadres had pre-selected the households and a very complicated process of negotiation was necessary to overcome this preselection. One way of surmounting the difficulty was to go to a pre-selected household followed by the next 20 households in one direction. The final sample thus included a few pre-selected households plus others not originally officially selected.

I prepared all the questionnaires in advance, questions being much more specific and detailed than in my previous study. Interestingly, in $1980 \mathrm{I}$ had to alter some of the questions after interviews at higher administrative levels and initial interviews in the households, because some of the questions were too complex and interpretative, or inappropriate to the precise location of the field research. However, it is still essential to prepare the questionnaires before entering the field, partly because the focus of the questions does not change, but also because of the limited access and exhausting nature of appraisal. It is easier to alter questionnaires than to begin afresh and prepared them from scratch. My questionnaires were quite tightly structured to allow for comparable data from each area and household, but one should always include an open-ended section at the end to allow for questions on subjects of unforeseen interest. In one household for example it may be an unusual marriage form that excites curiosity, in another a food habit, an extraordinary expenditure or observable item in the room.

I found I could not delegate any part of the research. Partly this was because there was no time to train assistants or to be sure that the questioning was similar 
in all households. Moreover it was necessary to check every single piece of arithmetic while in the household or in the production team or commune. This I learnt from experience, because after the first trip some of the figures just did not tally.

For accuracy in rapid appraisal the contextualisation of the household survey is important. Any discrepancies can be noted immediately. For example, if figures for a particular household seemed very high in terms of shopping, income, or expenditure of grain, it was possible to question household members more closely because I already had some data on what was expected in that neighbourhood. Also it was possible to ask the same question in different ways or of different household members if there seemed to be a discrepancy. One of the most common ways employed to check on information was to be both general and specific in questioning. For instance, when asking about shopping, questions such as "What do you usually spend?' and 'What do you usually buy?' would be followed by 'What did you buy this morning?' or 'How much did you spend this morning?' This proved quite effective in eliciting discrepancies. An example was the new free markets which had just been reestablished in 1980. There was still some question in people's minds about whether they should really use them, since they constituted a private sector, and hence smacked of 'bourgeois practice'. Informants might simultaneously 'never' or 'only very rarely' shop there, and yet have purchased articles that morning.

Finally, it is also important to know what sort of documentation can be inspected in the household. For instance, when seeking information on income there are the wage envelopes which are given out after each harvest, and which number each individual's input in terms of labour days and work and also how much money the fa mily has been given as income in cash and as income in grain. Some women had notebooks in which they had written down their housekeeping expenses, but this was not so common. Of course more documentation may be available in China than in other societies, as it is highly literate.

Making a rapid appraisal in China is helped by the fact that it is a highly organised society, and that there is actually a very small range of opportunities for differentials between households. Even so, what was readily acquired in a short time was basic data on households and some idea of inputs in terms of income and labour and their particular role in the provisioning, procuring and processing of food. More difficult to obtain were data on the distribution of familial funds or food consumption within the household. In other words, it was possible by means of rapid surveys to disaggregate the household in terms of inputs, but not so possible to break down intra- familial distribution. It was possible by questioning to learn who managed the family budget, household accounts and things like that, but not who controlled the expenditure. Nor does such questioning provide much idea of age or gender differentials in food consumption. It was very difficult to think of ways in which both the household and the individual within it could each be taken as units of measurement at the same time: in other words, both to ask individual questions and yet still treat the household as a unit of analysis. For instance, studies of food and nutrition elsewhere assume that women eat less than men, but in China there are widely-accepted norms of equal gender access to resources. In reply to the question 'Do the women of the household eat as much as the men?', the answer would undoubtedly have been 'Oh, of course, if they want to'. Again, the ration stamp does not actually indicate how much cooked food is allocated at meal times to the individual bowls. Also, much eating takes place outside the household in canteens. Visits were arranged to the canteens and workers were interviewed at the time of eating on their food intake, how much it cost and what they would eat at home before and after work. Certainly the size of the men's food bowls suggested that their canteen food intake far outweighed that of their female colleagues.

\section{Concluding Remarks}

The key issues in deciding the method, scope and depth of rapid appraisal possible in China are to decide which constraints are acceptable and which may invalidate the research. In terms of subject it may only be feasible to research areas for which data are easily attainable and less open to wide variations in interpretation by the informants. For example, it is less valuabie to ask informants for their opinions in the more intimate and politically sensitive areas of decision-making in a country like China, where there is a well-developed ideology, unless one has previously obtained the basic data on which interpretations rest and which the researcher can then interpret in the light of a broader research framework.

In terms of the location of research, certain constraints may be acceptable within broadly defined limits, especially in the case of China which is such a large and diverse country. At the present time it would be argued that any local data systematically collected in China are useful.

The question of accepting the help of local cadres is complicated and the degree to which their help is acceptable probably depends on the subject of the research. Straight household data may not be so open to cadre influence as subjects like family planning, where a cadre will not only be responsible for the implementation of the policy but she may even be paid 
by results. The cooperation of cadres is essential for access and is therefore a sufficient reason for accepting this constraint.

The use of an interpreter is not a disadvantage where the researcher understands the language and can keep a check: indeed, unless the researcher has some understanding of the language a bias may be introduced by the interpreter into the questions, let alone the answers, which again may influence or invalidate the findings. An interpreter can be useful in giving the researcher time to write down the answers, think of the next question, check any quantifiable data and generally observe items of interest within the household.

In general, there are no hard and fast rules underlying rapid appraisal. In the last resort it is the nature of society, the subject of enquiry, the alternative available documentation and preliminary investigation which will determined the field research methodology and particularly the feasibility of rapid appraisal. With an appropriate scope and focus a well-prepared household survey proved to be an effective means of completing a study of certain institutions such as marriage, the family and kin groups and the resource flows of the highly organised Chinese food system. Each of these surveys revealed the importance of certain variables in structuring women's lives, work and use of time. However, rapid surveys are less likely to prove such an effective method of eliciting information where there is a strong incentive to be secretive for tax or other purposes. Where there are strong ideological norms governing socio-economic or political relations, certain techniques, such as asking about both the general habit and specific occasions, can be incorporated into the survey and can be quite effective in pointing out discrepancies between social norms and social reality. This is especially relevant in a society where there are strong ideological norms governing gender relations.

\section{References}

Croll, Elisabeth, 1977, 'Jiang village: a household survey', China Quarterly, no 72, pp786-814, December

-1981, The Politics of Marriage in Contemporary China, Cambridge University Press

-1982a, "The Chinese household and its econony: urban and rural survey data', Queen Elisabeth House Contemporary China Centre Resource Paper, mimeo

-1982b, The Family Rice Bowl; food and the domestic economy in China, United Nations Research Institute for Social Development, Geneva; also published by Zed Press, London, 1983

Levi-Strauss, C. 1953, 'Social structure' in A. L. Kroeber (ed), Anthropology Today, University of Chicago Press, Illinois 